\title{
Comparison of nanohardness between coronal and radicular intertubular dentin
}

\author{
Toshiko INOUE${ }^{1}$, Makoto SAITO ${ }^{1}$, Masato YAMAMOTO², Kazuhiro DEBARI ${ }^{3}$, Keitatsu KOU ${ }^{3}$, Fumio NISHIMURA ${ }^{1}$ and \\ Takashi MIYAZAKI ${ }^{1}$ \\ ${ }^{1}$ Department of Oral Biomaterials and Technology, Showa University School of Dentistry, 1-5-8 Hatanodai, Shinagawa-ku, Tokyo 142-8555, Japan \\ ${ }^{2}$ Department of Chemistry, College of Arts and Sciences, Showa University, 4562 Kamiyoshida, Fujiyoshida-shi, Yamanashi 403-0005, Japan \\ ${ }^{3}$ EM Laboratory, Showa University, 1-5-8 Hatanodai, Shinagawa-ku, Tokyo 142-8555, Japan \\ Corresponding author, Toshiko INOUE; E-mail: inoue@dent.showa-u.ac.jp
}

\begin{abstract}
This study investigated the hardness and Young's modulus of coronal and radicular intertubular dentin. Ten bovine teeth were each divided into coronal and radicular groups, and the flat surfaces of the coronal and radicular dentin were subsequently processed along the tooth axis. The hardness and Young's modulus of the coronal and radicular intertubular dentin were evaluated using nanoindentation tests, at two locations per tooth. Mean hardness and Young's modulus values were statistically compared by one-way ANOVA and Fisher's PLSD test. The hardness of coronal intertubular dentin was $0.81 \pm 0.05 \mathrm{GPa}$ and that of radicular dentin was $0.55 \pm 0.02 \mathrm{GPa}$. Additionally, the Young's modulus of coronal intertubular dentin was $26.60 \pm 2.19 \mathrm{GPa}$ and that of radicular dentin was $20.89 \pm 1.10 \mathrm{GPa}$. Findings of this study revealed that the hardness and Young's modulus of coronal intertubular dentin were greater than those of radicular intertubular dentin.
\end{abstract}

Keywords: Dentin, Hardness, Intertubular dentin

Received Sep 8, 2008: Accepted Nov 11, 2008

\section{INTRODUCTION}

The understanding of the mechanical properties of dentin is very important for clinical diagnosis and in the evaluation of dental materials when considering the design or lifetime duration. Dentin is covered by enamel tissues, and coronal dentin is the interface between enamel and radicular dentin. Radicular dentin, in turn, is the interface between the bone and coronal dentin ${ }^{1)}$. Thus, dentin is constituted of coronal dentin and radicular dentin.

It has been reported that fracture behaviors between coronal and radicular dentin are different as indicated by strain concentration tests and impression-induced damage tests ${ }^{2)}$. In clinical dentistry, microtensile bond strengths are different between coronal and radicular dentin ${ }^{3,4)}$. Moreover, the ultimate tensile strength of coronal dentin differs from that of radicular dentin along the tooth axis. Tensile strength of radicular dentin is greater than that of coronal dentin ${ }^{5-7)}$. Tensile tests using dumbbell-shaped specimens are reportedly useful for identifying defects easily ${ }^{5,8-12)}$. The fracture surfaces of coronal dentin are different from those of radicular dentin as observed by scanning microscopy after tensile tests. In particular, the fracture surfaces of coronal intertubular dentin are smooth whereas those of radicular intertubular dentin are rough ${ }^{5}$.

However, a large sample size is needed when performing tensile tests, and dentinal tubules are known to vary in length between specimens ${ }^{13)}$. Additionally, dentinal tubules are composed of peritubular and intertubular dentin. It has been reported that the mechanical properties of dentin are dominated by those of intertubular dentin ${ }^{144}$. Therefore, it is important to consider the mechanical properties of intertubular dentin.

Reports are scarce when it comes to comparing the mechanical properties of coronal and radicular intertubular dentin. Hence, the aim of this study was to determine and compare the nanohardness and Young's modulus of coronal and radicular intertubular dentin. Indentation is widely used to evaluate hardness and Young's modulus for dentin ${ }^{1,15-23)}$. This is because nanoindentation results in very small indented regions, making it possible to clarify the intertubular dentin properties irrespective of peritubular dentin or the dentinal tubules.

\section{MATERIALS AND METHODS}

\section{Materials}

Bovine lower central incisors were extracted immediately after sacrifice from the animals assumed to be 2 to 2.5 years old according to their dental age. Fractured or poorly mineralized teeth were not included. Teeth were frozen within 3 hours of extraction and stored at $-12^{\circ} \mathrm{C}$ in a freezer until use. Before preparation, the teeth were defrosted by immersion in Hank's balanced salt solution at room 

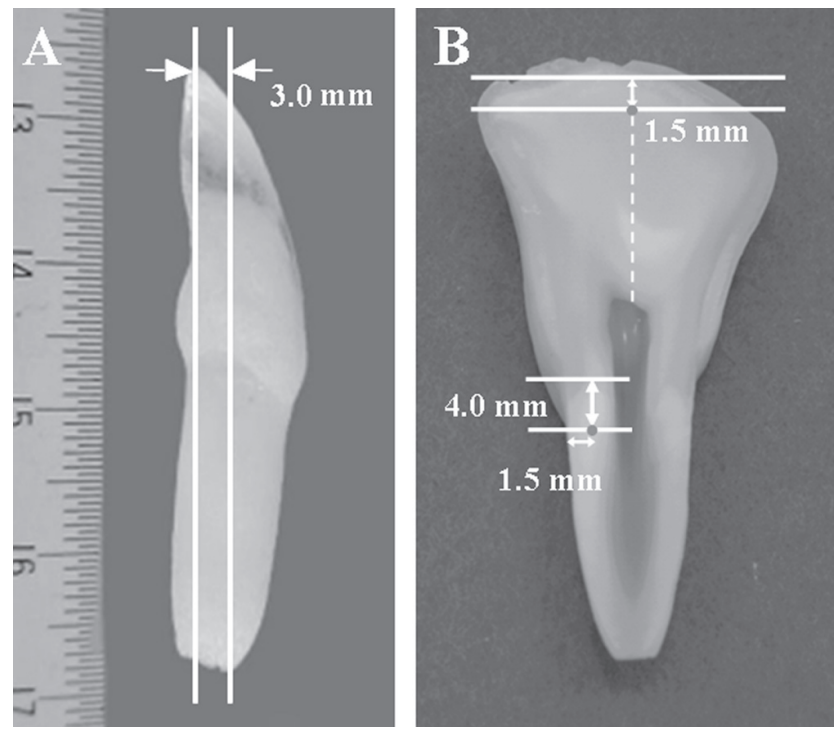

Fig. 1 (A) Schematic representation of the location of dentin slab in bovine tooth.

(B) The positions of coronal and radicular dentin for hardness and Young's modulus measurements.

temperature for 30 minutes.

\section{Preparation of specimens}

Ten bovine teeth were used in this study. A 3-mmthick dentin slab was harvested from each tooth using a low-speed cutting machine (Isomet, Buehler, Lake Bluff, IL, USA) under copious water cooling, whereby each slab was cut along the plane containing the incisal edge and the apex of the root (Fig. 1A). Next, the dentin slabs were sectioned into coronal and radicular portions using a diamond cutting disk at the cementoenamel junction. The coronal and radicular dentin of each tooth were embedded in acrylic with an epoxy resin (Palapress vario, Heraeus Kulzer GmbH, Hanau, Germany). The labial sides of the coronal and radicular dentin were prepared for indentation.

After sectioning, the specimens were sequentially polished with 600-, 800-, 1000-, 1200-, 1500-, and 2000-grit silicone carbide (SiC) papers (Maruto Instrument Co. Ltd., Tokyo, Japan), each for about 5 minutes under wet conditions. Final polishing was performed on each specimen with 15-, 9-, 6-, 3-, 1-, and $0.1-\mu \mathrm{m}$ diamond lapping films sequentially, each for about 20 minutes under wet conditions (Buehler, Lake Bluff, IL, USA). After polishing each segment, the smear layer and debris were removed by ultrasonic cleaning for 5 minutes. The polished specimens were stored in Hank's balanced salt solution at $4^{\circ} \mathrm{C}$ prior to use.

\section{Hardness and Young's modulus measurements}

The positions for hardness and Young's modulus

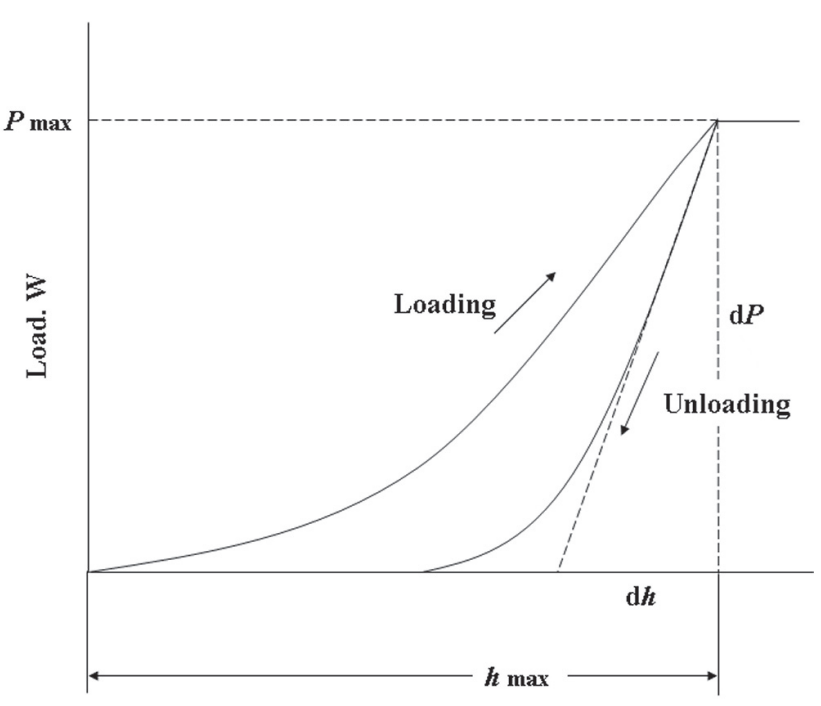

Fig. 2 Schematic representation of the load versus indenter displacement curve for an indentation experiment.

measurements are indicated in Fig. 1B. There were two focus areas, namely coronal dentin and radicular dentin. The indentation positions were as follows: the coronal area was $1.5 \mathrm{~mm}$ midway from the DEJ along the line including the edge of the coronal dentin and the center of the pulp chamber wall; the radicular area was $1.5 \mathrm{~mm}$ midway from the outer surface and $4 \mathrm{~mm}$ below the CEJ. A total of five triangular indentations were determined and recorded at different segments on the intertubular dentin of each tooth. The average data for each tooth was then taken from the five indentations, which were done at a distance of $10 \mu \mathrm{m}$ from each other. The hardness and Young's modulus results of the specimens were statistically analyzed by one-way ANOVA and Fisher's PLSD test (significance was accepted at $p<0.05$ ).

To measure hardness and Young's modulus, a dynamic hardness tester (DUH-W201, Shimadzu Corp., Kyoto, Japan) attached to a Berkovich indenter, a three-sided pyramid diamond probe, was used. Room temperature was maintained at $26 \pm 0.5^{\circ} \mathrm{C}$. Each specimen was placed on the stage of the tester with the specimen surface orientated parallel to the stage. The tip then approached the specimen at a velocity of $1 \mathrm{mN} / \mathrm{s}$. Hardness was measured using a force of up to $5 \mathrm{mN}$ to create a superficial indent on the specimen surface. After contact had been established, pressure was applied for 5 seconds.

During indentation, a curve describing the relationship between load $P$ and displacement $h$ was continuously monitored and recorded (Fig. 2). The 
mechanical properties of the material could be derived by analyzing the load-displacement data during the loading-unloading indentation cycle. Hardness, $H$, is given by Eq. (1) as follows:

$$
H=37.8 \times P_{\max } / h_{\max }^{2}
$$

where $P_{\max }$ is the maximum applied load and $h_{\max }$ is the indenter displacement at maximum load.

To determine Young's modulus from the force displacement data, the procedure outlined by Oliver and Pharr ${ }^{24)}$ was followed. Young's modulus, $E$, is given by Eq. (2) as follows:

$$
E=(\mathrm{d} P / \mathrm{d} h)(\sqrt{\pi} / 2 \sqrt{A})
$$

where $\mathrm{d} P / \mathrm{d} h$ is the slope of the unloading curve at maximum force and $A$ is the contact area created by the indentation.

Scanning electron microscope (SEM) observations and elemental analysis of coronal and radicular dentin The specimens were coated to a thickness of $200 \AA$ in a carbon coater (VC-100, Vacuum Device Inc., Ibaraki, Japan) after the indentation test. The indentations of each specimen were then observed using a scanning electron microscope (S-4500, Hitachi Ltd., Tokyo, Japan). A backscattered electron image was filmed using yttrium-aluminium-garnet (YAG) backscattered electron imaging and at $\times 2000$ magnification.

Additionally, an energy dispersive X-ray spectroscope (EMAX-7000, Horiba Ltd., Tokyo, Japan) was used to determine the elemental composition of each area. Average data of each tooth was obtained from the five sets of data near each indentation. In this manner, the $\mathrm{Ca}, \mathrm{P}$, and $\mathrm{Mg}$ concentrations as well as the $\mathrm{Ca} / \mathrm{P}$ ratio in coronal and radicular dentin were determined. The measurement area for these concentrations was $2 \mu \mathrm{m}$ $\times 2 \mu \mathrm{m}$, which was approximately the same as the hardness measurement area.

\section{RESULTS}

Hardness and Young's modulus measurements of coronal and radicular dentin

Figures $3 \mathrm{~A}$ and $3 \mathrm{~B}$ show the hardness and Young's modulus results of coronal and radicular intertubular dentin, which were obtained at two locations of each tooth using nanoindentation tests. The mean hardness and Young's modulus values were compared statistically by one-way ANOVA and Fisher's PLSD test (significance was accepted at $p<0.05$ ).

Hardness of coronal intertubular dentin was $0.81 \pm 0.05 \mathrm{GPa}$, while that of radicular dentin was $0.55 \pm 0.02 \mathrm{GPa}$. The Young's modulus of coronal
A

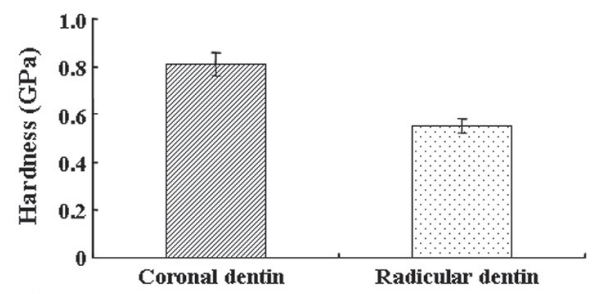

B

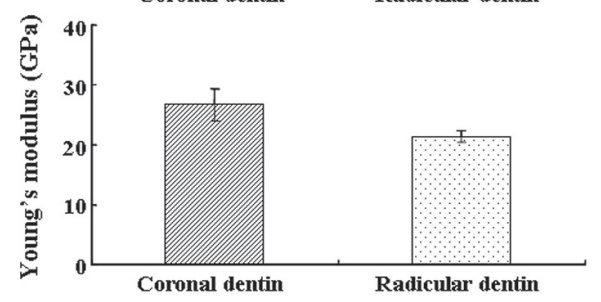

C

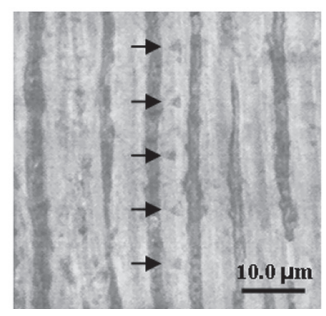

D

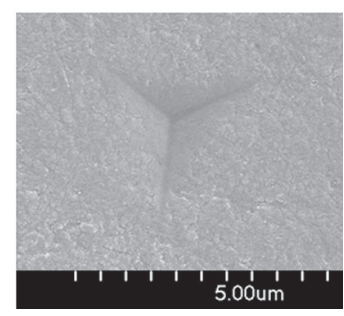

Fig. 3 (A) Hardness values of coronal and radicular dentin $(n=10)$.

(B) Young's moduli of coronal and radicular dentin $(n=10)$.

(C, D) Typical indentation images after the indentation test.
$\mathbf{A}$

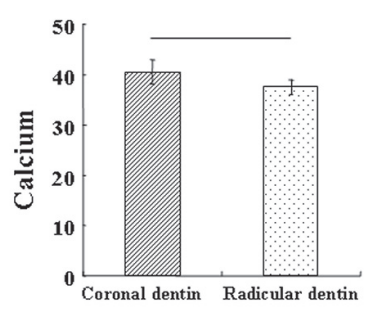

C

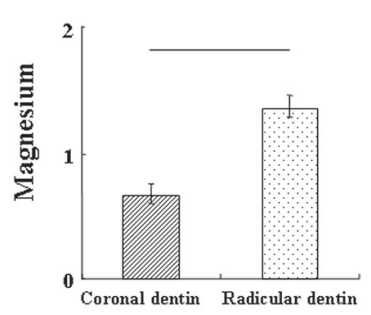

B

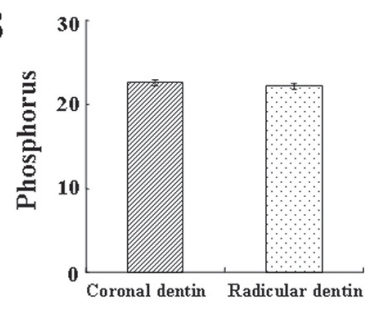

D

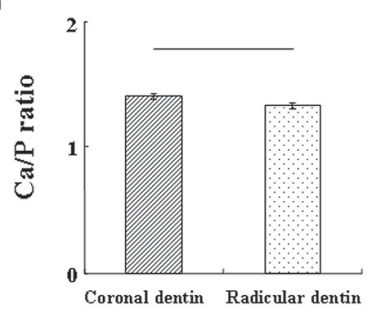

Fig. 4 Elemental compositions of coronal and radicular dentin. (A) $\mathrm{Ca}$ in wt\%; (B) $\mathrm{P}$ in wt\%; (C) $\mathrm{Mg}$ in wt\%; (D) $\mathrm{Ca} / \mathrm{P}$ ratio.

Vertical lines represent SD. The horizontal lines above the bars indicate that groups differ statistically from each other $(p<0.05)$. 
intertubular dentin was $26.60 \pm 2.19 \mathrm{GPa}$, while that of radicular dentin was $20.89 \pm 1.10 \mathrm{GPa}$. Results showed that the hardness and Young's modulus of coronal intertubular dentin were greater than those of radicular intertubular dentin.

\section{SEM observations and elemental analysis of coronal} and radicular dentin

The indentations on the specimens following the nanoindentation tests were confirmed using a microscope with a CCD camera under $\times 700$ magnification, as indicated in Fig. 3C. Arrows showed the indents in the intertubular dentin. Typical indentation cracks both of the coronal and radicular dentin were not seen in the scanning electron microscope images (Fig. 3D).

On elemental analysis, the obtained mineral contents of each group are indicated in Figs. 4A-D. The amount of $\mathrm{Ca}$ in coronal dentin was $41.22 \pm 0.88$ wt\%, while that in radicular dentin was $38.18 \pm 0.61$ wt\%. The P content in coronal dentin was $22.52 \pm 0.24$ wt\%, while that in radicular dentin was $22.01 \pm 0.31$ wt\%. The amount of $\mathrm{Mg}$ in coronal dentin was $0.67 \pm 0.09 \mathrm{wt} \%$, while that in radicular dentin was $1.37 \pm 0.11 \mathrm{wt} \%$. The $\mathrm{Ca} / \mathrm{P}$ ratio (MR) of coronal dentin was $1.43 \pm 0.02$, while that of radicular dentin was $1.34 \pm 0.02$. Results showed that the Ca content and $\mathrm{Ca} / \mathrm{P}$ molar ratio of coronal dentin were significantly higher than those of radicular dentin. In terms of $\mathrm{P}$ content, there were no significant differences between each dentin region. In terms of $\mathrm{Mg}$ content, that in coronal dentin was significantly lower than that in radicular dentin.

\section{DISCUSSION}

There have been many reports on dentin hardness over the past 70 years ${ }^{25-32}$. It is well known that the hardness of dentin varies depending on the area ${ }^{25-28)}$. Previous studies have used indentations to measure hardness. However, owing to the largeness of the indentation areas, measurements included not only intertubular dentin but also dentinal tubules and peritubular dentin. Consequently, the hardness values were merely a composite average.

The difference in hardness between coronal and radicular dentin stems from their differences in structure, i.e., tubular density, whereby it has been reported that tubular density differs between coronal and radicular dentin ${ }^{33)}$. As tubular density is closely correlated with the position between coronal and radicular dentin, it is not possible to determine from microindentation measurement methods whether decreased hardness is due to dentin morphology (increased tubular density) or due to differences in the material properties of the constituents of dentin. Incidentally, dentin consists of peritubular dentin, intertubular dentin, and dentin lumens.

Kinny et al. investigated the hardness of intertubular and peritubular dentin at two locations, near the dentino-enamel junction and near the pulp in coronal dentin ${ }^{13)}$. They confirmed that the hardness of intertubular dentin near the dentinoenamel junction was greater than that of intertubular dentin near the pulp. The hardness of intertubular dentin, but not that of peritubular dentin, differs depending on the site. Previous study has already reported that the Knoop hardness of radicular dentin was significantly lower than that of coronal dentin in bovine incisors ${ }^{2}$. Similarly in the present study, results showed that the hardness and Young's modulus of coronal intertubular dentin were greater than those of radicular intertubular dentin. In other words, our results were in agreement with those of previous study ${ }^{2)}$. We also confirmed that intertubular dentin exhibited statistically significant differences in hardness and Young's modulus according to the site under investigation. Table 1 shows the reported values of hardness and Young's modulus of dentin, where the hardness of intertubular dentin ranged

Table 1 Reported values of hardness and Young's modulus of dentin

\begin{tabular}{|c|c|c|c|c|}
\hline Type of teeth & Site & $\begin{array}{l}\text { Hardness } \\
\quad(\mathrm{GPa})\end{array}$ & $\begin{array}{l}\text { Young's modulus } \\
\text { (GPa) }\end{array}$ & Authors and dates \\
\hline Third molar & Coronal intertubular & & 20 & Kinny JH et al. (1999) ${ }^{14)}$ \\
\hline Premolar and canine & Coronal intertubular & $0.4-0.7$ & $18-27$ & Hosoya Y et al. $(2005)^{15)}$ \\
\hline Premolar & Coronal intertubular & 0.7 & 21 & Chung HK et al. $(2005)^{18)}$ \\
\hline Third molar & $\begin{array}{l}1 \mathrm{~mm} \text { superior to the cervical } \\
\text { margin }\end{array}$ & 0.8 & $20-24$ & Kinny JK et al. $(2003)^{19)}$ \\
\hline Premolar & Coronal intertubular & 0.9 & 15 & Poolthong S et al. $(2001)^{20)}$ \\
\hline Third molar & Coronal intertubular & $0.8-1.0$ & $18-21$ & Marshall GW et al. $(2001)^{21)}$ \\
\hline Third molar & Coronal intertubular & 0.8 & 20 & Marshall GW et al. $(2001)^{22)}$ \\
\hline Root & Radicular intertubular & $0.5-0.8$ & $24-25$ & Balooch M et al. $(2001)^{23)}$ \\
\hline
\end{tabular}


from 0.4 to $1.0 \mathrm{GPa}$ and that the Young's modulus ranged from 18 to $27 \mathrm{GPa}$. In the present study, our data were also within the range of these reported values.

Hardness tests measure the resistance of dentin to deformation caused by the penetration of an indenting stylus. This technique measures the indenter load as a function of depth of penetration from which the contact stiffness is obtained from the derivative of the unloading curve evaluated at the peak force. The modern theory of indentation, where force and stylus displacement are analyzed to measure Young's modulus, has been applied to mineralized tissues only in the last decade. The elastic properties of dentin are important for understanding the mechanical properties of calcified tissue. For this reason, nanoindentation has recently become a common technique for the determination of local mechanical properties of structural features in biological hard tissues.

To compare the fracture surfaces of coronal and radicular dentin, the tensile test has been used. It was previously shown that the collagen fibers in dentin contributed to the tensile strength of dentin $^{6,10)}$. The amount of collagen fibers in radicular dentin is greater than that in coronal dentin ${ }^{34}$. Therefore, the tensile strength of coronal dentin is lower than that of radicular dentin. As for dentin hardness, it is related to the mineral content ${ }^{14)}$. To date, there are no reports comparing the degree of mineralization of intertubular dentin between coronal and radicular dentin ${ }^{14)}$. Against this backdrop of information scarcity, we compared the mineral components of coronal and radicular dentin and showed that the $\mathrm{Ca} / \mathrm{P}$ ratio of coronal intertubular dentin was higher than that of radicular intertubular dentin. The $\mathrm{Ca} / \mathrm{P}$ ratio is closely correlated with the hardness value $^{35,36)}$. On this premise, we also confirmed that the mineral content contributed to the hardness of dentin.

The hardness and Young's modulus of dentin might be affected not only by region/location, but also by a multiplicity of factors such as animal species (e.g., human or bovine), type of tooth (e.g., molar or incisor), and human characteristics (e.g., age, sex, race, or environment). These variations need to be taken into account and studied in depth to the end of obtaining useful insight for clinical science.

\section{ACKNOWLEDGMENTS}

The authors gratefully acknowledge the financial support received from the High-Tech Research Center Project for Private Universities, matching fund subsidy from the Ministry of Education, Culture, Sports, Science and Technology of Japan, 2005-2008.

\section{REFERENCES}

1) Tesch W, Eidelman N, Roschger P, Goldenberg F, Klaushofer K, Fratzl P. Graded microstructure and mechanical properties of human crown dentin. Calcif Tissue Int 2001; 69: 147-157.

2) Wang R. Anisotropic fracture in bovine root and coronal dentin. Dent Mater 2005; 21: 429-436.

3) De Goes MF, Giannini M, Foxton RM, Nikaido T, Tagami J. Microtensile bond strength between crown and root dentin and two adhesive systems. J Prosthet Dent 2007; 97: 223-228.

4) Burrow MF, Sano H, Nakajima M, Harada N, Tagami J. Bond strength to crown and root dentin. Am J Dent 1996; 9: 223-229.

5) Inoue T, Takahashi H, Nishimura F. Anisotropy of tensile strengths of bovine dentin regarding dentinal tubule orientation and location. Dent Mater J 2002; 21: 32-43.

6) Miguez PA, Pereira PN, Atsawasuwan P, Yamauchi M. Collagen cross-linking and ultimate tensile strength in dentin. J Dent Res 2004; 83: 807-810.

7) Sano H, Ciucchi B, Matthews WG, Pashley DH. Tensile properties of mineralized and demineralized human and bovine dentin. J Dent Res 1994; 73: 1205-1211.

8) Inoue T, Miyazaki T, Nishimura F. Tensile strength and durability of bovine dentin. Dent Mater J 2007; 26: 348-354.

9) Tonami K, Takahashi H, Kato J, Nakano F, Nishimura F, Takagi Y, Kurosaki N. Effects of laser irradiation on tensile strength of bovine dentin. Photomed Laser Surg 2005; 23: 278-283.

10) Nakano F, Takahashi H, Nishimura F. Reinforcement mechanism of dentin mechanical properties by intracanal medicaments. Dent Mater J 1999; 18: 304-313.

11) Tonami K, Takahashi H. Effects of aging on tensile fatigue strength of bovine dentin. Dent Mater J 1997; 16: 156-169.

12) Tonami K, Takahashi H, Nishimura F. Effect of frozen storage and boiling on tensile strength of bovine dentin. Dent Mater J 1996; 15: 205-211.

13) Kinney JH, Balooch M, Marshall SJ, Marshall GW Jr, Weihs TP. Hardness and Young's modulus of human peritubular and intertubular dentine. Arch Oral Biol 1996; 41: 9-13.

14) Kinney JH, Balooch M, Marshall GW, Marshall SJ. A micromechanics model of the elastic properties of human dentin. Arch Oral Biol 1999; 44: 813-822.

15) Hosoya Y, Marshall GW. The nano-hardness and elastic modulus of sound deciduous canine dentin and young premolar dentin - preliminary study. J Mater Sci Mater Med 2005; 16: 1-8.

16) Zaslansky P, Friesem AA, Weiner S. Structure and mechanical properties of the soft zone separating bulk dentin and enamel in crowns of human teeth: insight into tooth function. J Struct Biol 2006; 153: 188-199.

17) Hairul Nizam BR, Lim CT, Chng HK, Yap AU. Nanoindentation study of human premolars subjected to bleaching agent. J Biomech 2005; 38: 2204-2211.

18) Chng HK, Ramli HN, Yap AU, Lim CT. Effect of 
hydrogen peroxide on intertubular dentine. J Dent 2005; 33: 363-369.

19) Kinney JH, Habelitz S, Marshall SJ, Marshall GW. The importance of intrafibrillar mineralization of collagen on the mechanical properties of dentin. $\mathrm{J}$ Dent Res 2003; 82: 957-961.

20) Poolthong S, Mori T, Swain MV. Determination of elastic modulus of dentin by small spherical diamond indenters. Dent Mater J 2001; 20: 227-236.

21) Marshall GW, Habelitz S, Gallagher R, Balooch M, Balooch G, Marshall SJ. Nanomechanical properties of hydrated carious human dentin. J Dent Res 2001; 80: 1768-1771.

22) Marshall GW Jr, Balooch M, Gallagher RR, Gansky SA, Marshall SJ. Mechanical properties of the dentinoenamel junction: AFM studies of nanohardness, elastic modulus, and fracture. J Biomed Mater Res 2001; 54: 87-95.

23) Balooch M, Demos SG, Kinney JH, Marshall GW, Balooch G, Marshall SJ. Local mechanical and optical properties of normal and transparent root dentin. J Mater Sci Mater Med 2001; 12: 507-514.

24) Oliver WC, Pharr GM. An improved technique for determining hardness and elastic modulus using load and displacement sensing indentation experiments. Journal of Materials Research 1992; 7: 1564-1583.

25) Gilmore RS, Pollack RP, Katz JL. Elastic properties of bovine dentin and enamel. Arch Oral Biol 1970; 15: 787-796.

26) Craig RG, Gehring PE, Peyton FA. Relation of structure to the microhardness of human dentin. J Dent Res 1959; 38: 624-630.

27) Craig RG, Peyton FA. The microhardness of enamel and dentin. J Dent Res 1958; 37: 661-668.
28) Fusayama T, Okuse K, Hosoda H. Relationship between hardness, discoloration, and microbial invasion in carious dentin. J Dent Res 1966; 45: 1033-1046.

29) Knoop F, Peters CG, Emerson WB. Sensitive pyramidal diamond tool for indentation measurements. J Res Natl Bur Stand 1939; 23: 3961.

30) Wright HN, Fenske EL. Factors involved in variability in hardness of tooth structures. J Dent Res 1938; 17: 297.

31) Hodge HC. Hardness tests on teeth. J Dent Res 1936; 15: 271-279.

32) Hodge HC, McKay H. The microhardness of teeth. J Am Dent Assoc 1933; 20: 227-233.

33) Schilke R, Lisson JA, Bauss O, Geurtsen W. Comparison of the number and diameter of dentinal tubules in human and bovine dentine by scanning electron microscopic investigation. Arch Oral Biol 2000; 45: 355-361.

34) Takagi Y, Nagai H, Sasaki S. Difference in noncollagenous matrix composition between crown and root dentin of bovine incisor. Calcif Tissue Int 1988; 42: 97-103.

35) Sakoolnamarka R, Burrow MF, Swain M, Tyas MJ. Microhardness and $\mathrm{Ca}$ : $\mathrm{P}$ ratio of carious and Carisolv treated caries-affected dentine using an ultra-micro-indentation system and energy dispersive analysis of x-rays - a pilot study. Aust Dent J 2005; 50: 246-250.

36) Kodaka T, Debari K, Yamada M. Physico-chemical and morphological studies of horse dentin. J Electron Microsc (Tokyo) 1991; 40: 385-391. 